\title{
Perinatal factors influencing mother-to-child HBV transmission.
}

\author{
Fei Chen ${ }^{1}$, Xiaoqing $\mathrm{Li}^{2}$, Tian Yuan ${ }^{1}$, Jinjin Chen ${ }^{1}$, Wang Yu${ }^{1}$, Guangjun Yu${ }^{1 *}$ \\ ${ }^{1}$ Shanghai Children's Hospital, Children's Hospital Affiliated to Shanghai Jiaotong University, 200062, Shanghai, PR \\ China
}

${ }^{2}$ Songjiang Gynecology Infantile Health Hospital of Shanghai, 201620, Shanghai, PR China

\begin{abstract}
Background: Chronic hepatitis B virus (HBV) infection remains a key public health problem. In China, mother-to-child transmission is recognized as the major transmission pathway. The exact mechanism by which HBV enters the fetus through the maternal placenta is unclear, hampering the development of preventative interventions.

Objective: We aimed to identify perinatal factors influencing intrauterine transmission as determined by hepatitis B surface antigen (HBsAg) positivity $12 \mathrm{~h}$ after birth.

Study design: A total of $343 \mathrm{HBsAg}(+)$ newborns with $\mathrm{HBV}(+)$ mothers were included in this study. The maternal marker expression pattern as well as associations of maternal HBsAg status with multiple perinatal risk factors for transmission (including sex, fetal position, mode of delivery, gestational age, number of complications, and infant HBV marker levels were analyzed.

Results: The majority of $\mathrm{HBsAg}(+)$ newborns were also $\mathrm{HBeAg}(+)$. The $\mathrm{HBeAg}$ and anti-HBe titers were significant higher in newborns from HBsAg(+) mothers than HBsAg(-) mothers $(\mathbf{P}=0.000)$. The frequency of $\geq 2$ complications was significant higher in $\mathrm{HBsAg}(+)$ mothers than $\mathrm{HBsAg(-)}$ mothers $(p=0.023)$. There was no significant difference in offspring in sex, mode of delivery, in utero position, or gestational age between HBsAg( + ) and HBsAg(-) mothers (all $P \geq 0.05$ ).

Conclusion: The HBsAg(+) newborns of $\mathrm{HBsAg}(+)$ mothers showed higher $\mathrm{HBV}$ viral replication rates than those of HBsAg(-) mothers. Maternal HBsAg-positivity and multiple pregnancy complications were significant risk factors for uterine mother-to-child $\mathrm{HBV}$ transmission. Offspring of $\mathrm{HBV}$-infected mothers should be screened regularly for HBV markers to identify carriers.
\end{abstract}

Keywords: Hepatitis B virus, Mother-to-child transmission, Perinatal factor, Hepatitis B e antigen li.

Accepted on November 17, 2017

\section{Introduction}

Chronic infection by hepatitis B virus (HBV) is a global public health issue afflicting 240 million people worldwide [1]. According to previous studies in HBV-endemic areas, infection occurs mainly in infancy and early childhood, with mother-tochild transmission (MTCT), also called vertical transmission, accounting for more than $90 \%$ of chronic infection in newborns and up to $50 \%$ in children less than 3 years old [2]. In China, the rate of $\mathrm{HBV}$ infection among women of childbearing age is still high (7.18\%) [3] and MTCT may occur prenatally, during delivery, or in the early postpartum period.

Hepatitis B virus vaccination has been adopted by national immunization programs in China and many other countries. The World Health Organization recommends administration of HBV active immunization with or without Hepatitis B immunoglobulins (HBIG) within $12 \mathrm{~h}$ after birth to newborns born to hepatitis B surface antigen (HBsAg)-positive mothers to reduce postpartum MTCT, and this is now applied as standard procedure for such infants [1]. The exact mechanism by which HBV enters the fetus through the maternal placenta remains unclear. The HBsAg is detectable in amniotic fluid, cord blood, breast milk, vaginal fluid, and infant gastric contents, suggesting multiple routes for MTCT [4,5].

To examine the factors associated with intrauterine infection, we measured marker expression at $12 \mathrm{~h}$ postnatal. The aim of this study is to analyze the perinatal factors that may influence MTCT, such as sex, fetal position, mode of delivery, gestational age (GA), number of complications, and infant HBV marker levels.

\section{Materials and Methods}

\section{Study subjects}

This study enrolled newborns HBsAg-positive $[\mathrm{HBsAg}(+)]$ as determined by peripheral blood testing within $12 \mathrm{~h}$ after birth and before HBIG injection at Songjiang Gynecology Infantile Health Hospital of Shanghai. A total 1113 neonates were screened from May 2013 to November 2015. Finally, serum 
samples from $343 \mathrm{HBsAg}(+)$ newborns and their mothers were analyzed for HBV markers. The study protocol was reviewed and approved by Songjiang Gynecology Infantile Health Hospital of Shanghai ethics committee (2012-III -21). Informed written consent was obtained from all parents.

\section{Definitions of groups}

For statistical analyses, maternal $\mathrm{HBV}$ status was divided according to the combination of antigen and antibody HBV markers (HBsAg, anti-HBs, HBeAg, anti-HBe, anti-HBc), mode of delivery into spontaneous and caesarean section, and maternal complications of pregnancy into none; one complication, and $\geq 2$ complications.

\section{HBV serological assay}

Peripheral blood samples $(5 \mathrm{~mL})$ were acquired from newborns within $12 \mathrm{~h}$ after delivery (prior to inoculations with HBIG and HBV vaccines) and processed within $12 \mathrm{~h}$ of collection. All newborns received the government-funded 3 doses of approved HBV vaccine (10 mg/dose). Administration of HBIG (100 IU) was successfully given within 24 hours after birth. Serum HBV markers were determined using reagents from Roche Diagnostics and a Cobas e601 analyzer (Roche Diagnostic GmbH, Mannheim, Germany).

\section{Semi-quantification of serum HBV markers}

Serum HBV markers were determined based on the competition principle by ELISA using reagents from Roche on a Cobas e601 analyzer. Samples were considered positive based on the following cutoff indexes: HBsAg $\geq 1$; anti-HBs $\geq$ $10 \mathrm{mIU} / \mathrm{mL} ; \mathrm{HBeAg} \geq 1 ;$ anti-HBe $\geq 1 ;$ anti-HBc $\geq 1$.

\section{Definition of newborn infants $\mathrm{HBV}$ infection and complications}

HBsAg positivity in peripheral blood at $12 \mathrm{~h}$ after birth was considered evidence of mother-to-child intrauterine $\mathrm{HBV}$ transmission [6]. Definitions of complications were according to "Obstetrics and gynecology" [7].

\section{Statistical analysis}

The chi-square test and Student's t-test were applied to evaluate the differences between categorical variables and continuous variables, respectively. The Wilcoxon rank sum test was used to compare the differences in HBV marker titers among groups. All statistical tests were two-sided and performed using SPSS 18.0 for Windows (SPSS, Chicago, IL). A P value of $<0.05$ was considered statistically significant.

\section{Results}

\section{Perinatal parameters of HBsAg( + ) newborns}

Average GA was $39.4 \pm 1.25 \mathrm{w}$ (range, 34.7-41.7 w). Average BW was $3336 \pm 420 \mathrm{~g}$ (range, 1900-4350 w). The majority of HBsAg $(+)$ infants $(89.8 \%)$ were in the LOA position with only
$2.92 \%$ in ROA and LSA positions secondly, respectively (Table 1). The most common maternal complication was anemia $(29.4 \%)$, followed by diabetes $(14.3 \%)$ (Table 2$)$. The five most frequent combinations of $\geq 2$ complications were anemia and hypothyroidism $(2.3 \%)$, anemia and diabetes $(2 \%)$, anemia and premature rupture of fetal membranes $(2 \%)$, anemia plus abnormal placental position $(2.0 \%)$, and anemia with fetal distress $(1.5 \%)$.

Table 1. Perinatal parameters of $\mathrm{HBs} \mathrm{Ag}(+)$ newborns.

\begin{tabular}{|c|c|c|}
\hline Perinatal factors & Frequency, $\mathbf{n}$ & $\%$ \\
\hline \multicolumn{3}{|l|}{ Sex } \\
\hline male & 178 & 51.9 \\
\hline female & 165 & 48.1 \\
\hline \multicolumn{3}{|l|}{ Position of fetus } \\
\hline LOA (Left Occiput Anterior) & 308 & 89.80 \\
\hline LOT (Left Occipito Transverse) & 10 & 2.92 \\
\hline LOP (left Occipito Posterior) & 10 & 2.92 \\
\hline ROA (Right Occiput Anterior) & 6 & 1.75 \\
\hline ROT (Right Occipito Transverse) & 4 & 1.17 \\
\hline ROP (Right Occiput Posterior) & 2 & 0.58 \\
\hline LSA (left Sacro Anterior) & 1 & 0.29 \\
\hline RSA (Right Sacro Anterior) & 1 & 0.29 \\
\hline RST (Right Sacro Transverse) & 1 & 0.29 \\
\hline \multicolumn{3}{|l|}{ Mode of the delivery } \\
\hline spontaneous delivery & 204 & 59.5 \\
\hline caesarean section & 139 & 40.5 \\
\hline \multicolumn{3}{|c|}{ Maternal complications during pregnancy } \\
\hline None & 170 & 49.6 \\
\hline One complication & 125 & 36.4 \\
\hline$\geq 2$ complications & 40 & 11.7 \\
\hline
\end{tabular}

Table 2. Maternal complications during pregnancy.

\begin{tabular}{ll}
\hline Complication & $\mathbf{n}^{*}$ \\
\hline Anemia & 101 \\
\hline Diabetes & 49 \\
\hline Fetal Distress & 25 \\
\hline Hypothyroidism & 21 \\
\hline Premature rupture of fetal membranes & 15 \\
\hline Cholestasis & 10 \\
\hline Abnormal placental position & 9 \\
\hline Hypertension & 6 \\
\hline Thrombocytopenia & 5 \\
\hline
\end{tabular}




\begin{tabular}{ll}
\hline Fibroid & 3 \\
\hline Oligohydramnios & 2 \\
\hline Hepatic dysfunction & 2 \\
\hline Postpartum hemorrhage & 1 \\
\hline Umbilical cord rupture & 1 \\
\hline Intrauterine growth retardation & 1 \\
\hline *out of 341 women & \\
\hline
\end{tabular}

\section{Maternal HBV marker profile}

There were $15 \mathrm{HBV}$ marker combinations among mothers of the $343 \mathrm{HBsAg}(+)$ newborns (Table 3), of which the most common was $\mathrm{HBeAg}(+) / \operatorname{anti}-\mathrm{HBc}(+)(43.7 \%)$, followed by anti-HBc(+), $\mathrm{HBsAg}(+) / \mathrm{HBeAg}(+) / \operatorname{anti}-\mathrm{HBc}(+)(23.3 \%)$, and $\mathrm{HBsAg}(+) / \operatorname{anti}-\mathrm{HBe}(+) / \operatorname{anti}-\mathrm{HBc}(+)(17.5 \%)$.

\section{Associations of maternal HBsAg status with infant $\mathrm{HBV}$ marker status and perinatal factors}

The 343 maternal peripheral blood samples were divided into two groups: $\mathrm{HBsAg}(+)$ and $\mathrm{HBsAg}(-) .82(24 \%)$ infants were born to $\mathrm{HBsAg}(+)$ mothers. The rate of $\geq 2$ maternal complications was significantly higher in $\mathrm{HBsAg}(+)$ mothers than $\operatorname{HBsAg}(-)$ mothers $(p=0.023)$, whereas there was no significant difference in offspring sex, mode of delivery, uterine position, GA or BW between the two groups $(\mathrm{P} \geq 0.05)$ (Table 4). The titers of $\mathrm{HBeAg}$ and anti-HBe were significant higher in newborns of the $82 \mathrm{HBsAg}(+)$ mothers than in infants of the $\mathrm{HBsAg}(-)$ mothers $(\mathrm{P}=0.000)$, while HBsAg titer was higher in newborns from $\operatorname{HBs} \mathrm{Ag}(-)$ mothers. In total, $70.3 \%$ of infants were $\mathrm{HBs} \mathrm{Ag}(+) / \mathrm{HBeAg}(+)$ as defined by $\geq 1$ for both.

Table 3. HBV marker status of mothers $(n=341)$.

\begin{tabular}{lll}
\hline Status of HBV makers & Frequency, $\mathbf{n}$ & $\%$ \\
\hline $\mathrm{HBeAg}(+) / \mathrm{anti}-\mathrm{HBc}(+)$ & 150 & 43.7 \\
\hline anti-HBc(+) & 80 & 23.3 \\
\hline $\mathrm{HBsAg}(+) / \mathrm{HBeAg}(+) / a n t i-H B c(+)$ & 60 & 17.5 \\
\hline $\mathrm{HBsAg}(+) / a n t i-H B e(+) / a n t i-H B c(+)$ & 16 & 4.7 \\
\hline anti-HBs(+)/anti-HBe$(+) / a n t i-H B c(+)$ & 7 & 2.0 \\
\hline $\mathrm{HBeAg}(+) / a n t i-H B e(+) / a n t i-H B c(+)$ & 5 & 1.5 \\
\hline anti-HBs(+) & 4 & 1.2 \\
\hline anti-HBs(+)/anti-HBc(+) & 4 & 1.2 \\
\hline
\end{tabular}

\begin{tabular}{|c|c|c|}
\hline anti-HBe(+)/anti-HBc(+) & 4 & 1.2 \\
\hline $\mathrm{HBsAg}(+) / a n t i-H B c(+)$ & 3 & 0.9 \\
\hline $\mathrm{HBsAg}(+) /$ anti-HBs$(+) /$ anti-HBe$(+) /$ anti-HBc(+) & 3 & 0.9 \\
\hline anti-HBs(+)/HBeAg(+)/anti-HBc(+) & 3 & 0.9 \\
\hline $\mathrm{HBsAg}(+)$ & 2 & 0.6 \\
\hline anti-HBe(+) & 2 & 0.6 \\
\hline Total & 343 & 100 \\
\hline \multicolumn{3}{|c|}{$\mathrm{HBsAg}(+)$ : hepatitis B surface antigen positivity } \\
\hline \multicolumn{3}{|l|}{$\mathrm{HBeAg}(+)$ : hepatitis B e antigen positivity } \\
\hline \multicolumn{3}{|l|}{ anti-HBe(+): anti- hepatitis B e antibody positivity } \\
\hline anti-HBc(+): anti- hepatitis B core antibody pos & tivity & \\
\hline
\end{tabular}

\section{Discussion}

Chronic hepatitis $\mathrm{B}$ virus (HBV) infection remains a critical public health problem in China, and MTCT during the perinatal period is considered the most important reason for the failure of passive-active immunoprophylaxis [8-10]. If the fetus cannot remove the hepatitis B virus from the mother, the infant with carry the virus chronically, and $9 \%$ will develop chronic HBV infection in adulthood [1]. The mechanisms by which HBV enters the fetus through the human placenta are still unclear. In the mid 1980's, immunological pathology and molecular biology techniques detected hepatitis $\mathrm{B}$ virus in the liver cells of stillbirths from HBV-positive mothers, confirming intrauterine infection. It is generally accepted that neonatal blood HBsAg positivity or HBV-DNA positivity $[6,11,12]$ is indicative of intrauterine infection. Here we show that neonatal mother-to-child infection is strongly associated with maternal viral status and pregnancy complications.

In this study, the titers of $\mathrm{HBeAg}$ and anti-HBe were related to the mothers' HBsAg status. Vertical transmission of HBV can occur by three routes: intrauterine transmission through the placenta, intrapartum transmission, and postnatal transmission through breast milk [13]. The latter two modes of transmission can be blocked by HBIG and HBV vaccines, but there is currently no effective preventive measure for intrauterine transmission by placenta during pregnancy [14]. Intrapartum transmission means a small amount of maternal blood into the fetal blood circulation caused by leakage the postpartum horizontal transmission due to placental villous vascular contraction of the uterus rupture when delivery. Studies on HBV-related intrauterine transmission have found that infection is related to transmission of maternal $\mathrm{HBsAg}, \mathrm{HBeAg}$ titer, and HBV-DNA content, which is similar to this study.

Table 4. Associations of maternal HBsAg status with perinatal factors and newborn HBV marker titers.

\begin{tabular}{lllll}
\hline & Maternal HBsAg(+) & Maternal HBsAg(-) & P or t value & \\
\hline Sex (male:female) & $44: 38$ & $134: 127$ & 0.134 \\
\hline GA & $39.52 \pm 1.21$ & $39.38 \pm 1.26$ & 0.714 \\
\hline
\end{tabular}




\begin{tabular}{|c|c|c|c|c|}
\hline BW & $3271 \pm 440$ & $3356 \pm 412$ & -1.607 & 0.109 \\
\hline Position of fetus (LOA) & $72(87.8 \%)$ & $236(90.4 \%)$ & 9.039 & 0.339 \\
\hline Mode of the delivery & & & 1.190 & 0.275 \\
\hline Spontaneous delivery & $53(64.6 \%)$ & $151(57.9 \%)$ & & \\
\hline Caesarean section & $29(35.4 \%)$ & $110(42.1 \%)$ & & \\
\hline Maternal complications during pregnancy & & & 7.577 & $0.023^{*}$ \\
\hline None & $37(45.1 \%)$ & 133 (51\%) & & \\
\hline One complication & $26(31.7 \%)$ & $99(37.9 \%)$ & & \\
\hline$\geq 2$ complications & $19(23.2 \%)$ & $29(1.1 \%)$ & & \\
\hline \multicolumn{5}{|l|}{ Semi-quantification of newborn HBV markers } \\
\hline HBsAg & $2367.59 \pm 205$ & $3236.75 \pm 161.90$ & -2.795 & $0.005^{*}$ \\
\hline anti-HBs (mIU/mL) & $5.23 \pm 2.21$ & $12.67 \pm 5.22$ & -0.792 & 0.429 \\
\hline $\mathrm{HBeAg}$ & $1045.25 \pm 67.33$ & $661.74 \pm 40.87$ & 4.670 & $0.000^{*}$ \\
\hline anti-HBe & $6.17 \pm 0.40$ & $4.26 \pm 0.22$ & 4.272 & $0.000^{*}$ \\
\hline anti-HBc & $0.02 \pm 0.01$ & $0.04 \pm 0.01$ & -0.933 & 0.352 \\
\hline
\end{tabular}

Data presented as number $(n)$ or mean $\pm S D$.

Interesting, we found $\mathrm{HBsAg}(+)$ mother is high risk of more complications during pregnancy. Most of the complications are easy to injure the placental barrier. Fetal and maternal circulatory systems are separated but can exchange substances through the placental barrier. Reports claimed that it is difficult for HBsAg to pass through the normal placental barrier, while $\mathrm{HBeAg}$ can pass through easily $[15,16]$. $\mathrm{HBeAg}$ is a major component of the virus nucleocapsid polypeptide and circulates in blood during active viral replication (i.e., when the host is infectious) [17]. It can exist in both a free state or in a IgG complex in the blood, and the complex can traverse the placenta and enter the fetal blood circulation. The immature fetal immune system can produce tolerance to $\mathrm{HBeAg}$, so HBV accumulates mutations that minimize the expression of epitopes recognized by $\mathrm{CD} 8+\mathrm{T}$ cells, particularly in the enhancer II/basal core promoter/precore (EnhII/BCP/preC) region and the preS/S regions, which may impair cytotoxic $\mathrm{T}$ cell function necessary to remove HBV from infected liver cells $[18,19]$. Therefore, $\mathrm{HBeAg}$ can enter the fetal circulation and interfere with immune cell function and even affect the specificity of antibodies, resulting in fetal infection [20-22]. In the study, infants of $\mathrm{HBsAg}(+)$ mothers exhibited higher $\mathrm{HBeAg}$ and $\mathrm{HBeAb}$ titers than infants of $\mathrm{HBsAg}(-)$ mothers. Thus, the risk of infants' chronic hepatitis $\mathrm{B}$ is higher in HBsAg(+) mothers.

In this study, we found that $\operatorname{HBsAg}(+)$ mothers were significantly more prone to complications than $\mathrm{HBsAg}(-)$ mothers, including fetal distress (6/19 cases), abnormal placental position (5 cases), premature rupture of fetal membranes ( 3 cases), and postpartum hemorrhage ( 1 case). It appears that placental leakage greatly increases the probability of intrauterine MTCT, as the virus does not easily pass through the intact barrier. In late pregnancy, women produce large amounts of estrogen, which is metabolized by the liver. Estrogen inactivation is reduced when liver cells are injured by HBV infection, which causes the incidence of postpartum hemorrhage. Maternal HBV infection can also markedly increase the incidence of fetal distress as infected mothers may develop placental chorionic vascular disease, which impairs placental circulation. During delivery, a small amount of maternal blood leaks into the fetal circulation during contraction of the uterus, and abnormal placenta position was recognized as a risk factor for maternal blood leakage. Therefore, $\operatorname{HBs} A g(+)$ women with multiple pregnancy complications are at highest risk for MTCT of HBV infection, and so maybe receive active intervention $[23,24]$.

Of all newborns positive for $\mathrm{HBsAg}(+)$, those from $\mathrm{HBsAg}(+)$ mothers showed significantly higher HBV viral replication than those from $\mathrm{HBsAg}(-)$ mothers. Mothers with $\mathrm{HBsAg}(+)$ status and multiple pregnancy complications were at highest risk of mother-to-child HBV transmission. Thus, this population should be targeted for preventative therapy. Newborns of infected mothers should be screened regularly for HBV markers to detect chronic carriers.

\section{References}

1. Goyal A, Murray JM. The impact of vaccination and antiviral therapy on hepatitis $\mathrm{B}$ and hepatitis D epidemiology. PLoS One 2014; 14: e110143.

2. Ma L, Alla NR, Li X, Mynbaev OA, Shi Z. Mother-to-child transmission of HBV: review of current clinical management and prevention strategies. Rev Med Virol 2014; 24: 396-406. 
3. Han GR, Xu CL, Zhao W, Yang YF. Management of chronic hepatitis B in pregnancy. World J Gastroenterol 2012; 18: 4517-4521.

4. Li Z, Hou X, Cao G. Is mother-to-infant transmission the most important factor for persistent HBV infection? Emerg Microbes Infect 2015; 4: e30.

5. Hanaoka M, Hisano M, Hama I, Tsukamoto K, Ito R, Ito Y, Sago H, Matsui A, Yamaguchi K. Hepatitis B virus surface antibody titers in babies administered hepatitis B immune globulin both intravenously and intramuscularly after birth. J Matern Fetal Neonatal Med 2016; 29: 1945-1948.

6. Xu YY, Liu HH, Zhong YW, Liu C, Wang Y, Jia LL, Qiao F, Li XX, Zhang CF, Li SL, Li P, Song HB, Li Q. Peripheral blood mononuclear cell traffic plays a crucial role in mother-to-infant transmission of hepatitis B virus. Int J Biol Sci 2015; 11: 266-273.

7. Zeyi C. Obstetrics and Gynecology (1st Edtn). Beijing People's Health Press, Beijing, China, 2008.

8. Abara WE, Cha S, Malik T, DeSimone MS, Schumann B, Mallada E, Klemme M, Aguon V, Santos AM, Collier M, Kamb M. Hepatitis B surface antigen screening among pregnant women and care of infants of hepatitis B surface antigen-positive mothers-Guam, 2014. MMWR Morb Mortal Wkly Rep 2017; 66: 506-508.

9. Manyahi J, Msigwa Y, Mhimbira F, Majigo M. High seroprevalence of hepatitis B virus and human immunodeficiency virus infections among pregnant women attending antenatal clinic at Temeke municipal health facilities, Dar es Salaam, Tanzania: a cross sectional study. BMC Pregnancy Childbirth 2017; 17: 109.

10. van Schalkwyk J, Nourmoussavi M, Massey A, Gustafson R, Brodkin E, Petric M, Krajden M, Dobson S, Buxton J, Bigham M, Pick N, Schreiber R, Sherlock CH, Money D, Yoshida EM. Missed opportunities for prevention of perinatal transmission of hepatitis $\mathrm{B}$ : a retrospective cohort study. Can J Gastroenterol Hepatol 2014; 28: 525-528.

11. Li XM, Yang YB, Hou HY, Shi ZJ, Shen HM, Teng BQ, Li AM, Shi MF, Zou L. Interruption of HBV intrauterine transmission: a clinical study. World J Gastroenterol 2003; 9: 1501-1503.

12. Zhang H, Pan CQ, Pang Q, Tian R, Yan M, Liu X. Telbivudine or lamivudine use in late pregnancy safely reduces perinatal transmission of hepatitis $\mathrm{B}$ virus in reallife practice. Hepatology 2014; 60: 468-476.

13. Navabakhsh B, Mehrabi N, Estakhri A, Mohamadnejad M, Poustchi H. Hepatitis B Virus infection during pregnancy: transmission and prevention. Middle East J Dig Dis 2011; 3: 92-102.

14. Eke AC, Eleje GU, Eke UA, Xia Y, Liu J. Hepatitis B immunoglobulin during pregnancy for prevention of mother-to-child transmission of hepatitis B virus. Cochrane Database Syst Rev 2017; 11: CD008545.

15. Ma L, Alla NR, Li X, Mynbaev OA, Shi Z. Mother-to-child transmission of HBV: review of current clinical management and prevention strategies. Rev Med Virol 2014; 24: 396-406.

16. Cheung KW, Seto MT, Wong SF. Towards complete eradication of hepatitis $\mathrm{B}$ infection from perinatal transmission: review of the mechanisms of in utero infection and the use of antiviral treatment during pregnancy. Eur J Obstet Gynecol Reprod Biol 2013; 169: 17-23.

17. Deqiu H, Yanmei L, Kangming C, Ling L. Examination of hepatitis marker in cord blood and prevention of Hepatitis B infection in uterus. Modern Hospital 2008; 8: 64-65.

18. Huang Y, Lok AS. Viral factors and outcomes of chronic HBV infection. Am J Gastroenterol 2011; 106: 93-95.

19. Yin J, Xie J, Zhang H, Shen Q, Han L, Lu W, Han Y, Li C, Ni W, Wang H, Cao G. Significant association of different preS mutations with hepatitis B-related cirrhosis or hepatocellular carcinoma. J Gastroenterol 2010; 45: 1063-1071.

20. Petrova M, Kamburov V. Breastfeeding and chronic HBV infection: clinical and social implications. World J Gastroenterol 2010; 16: 5042-5046.

21. Lv N, Chu XD, Sun YH, Zhao SY, Li PL, Chen X. Analysis on the outcomes of hepatitis $\mathrm{B}$ virus perinatal vertical transmission: nested case-control study. Eur J Gastroenterol Hepatol 2014; 26: 1286-1291.

22. Zhang Z, Chen C, Li Z, Wu YH, Xiao XM. Individualized management of pregnant women with high hepatitis $B$ virus DNA levels. World J Gastroenterol 2014; 20: 12056-12061.

23. Sun W, Ma L, Hao A, Liu W, Song M, Li M, Xin Y. Predictive value of telbivudine in preventing mother-toinfant transmission of hepatitis B virus in pregnant women with high viremia. Zhonghua Gan Zang Bing Za Zhi 2015; 23: 180-183.

24. Bleich LM, Swenson ES. Prevention of neonatal hepatitis B virus transmission. J Clin Gastroenterol 2014; 48: 765-772.

\section{*Correspondence to}

Guangjun $\mathrm{Yu}$

Shanghai Children's Hospital

Children's Hospital Affiliated to Shanghai Jiaotong University

PR China 